\title{
Molecular structure, first order hyperpolarizability, NBO and HOMO-LUMO analysis of cinnoline-4- carboxylic acid
}

\author{
S.Sindhu ${ }^{1}$, S. Muthu ${ }^{2^{*}}$ M. Raja ${ }^{3}$, R. Raj Muhamed ${ }^{3}$ \\ ${ }^{1}$ Department of Physics, Vels University, Pallavaram, Chennai-117, Tamilnadu, India \\ ${ }^{2}$ Department of Physics, Arignar Anna Govt. Arts College, Cheyyar, 604407, Tamilnadu, India \\ ${ }^{3}$ Department of Physics, Jamal Mohamed College, Tiruchirappalli-620020, Tamilnadu, India
}

\begin{abstract}
In this work, we reported theoretical investigations on molecular structure of cinnoline-4-carboxylic acid (CN4C). The molecular geometry and NLO have been calculated by using density functional theory B3LYP method with 6-311++G(d,p) basis set. The first order hyperpolarizability $\left(\beta_{\text {tot }}\right)$ of this molecular system and related properties $(\beta, \mu$ and $\Delta \alpha)$ are calculated using B3LYP/6$311++G(d, p)$ methods based on the finite-field approach. Stability of the molecule arising from hyper-conjugative interactions and charge delocalization has been analyzed using natural bond orbital analysis (NBO). The evaluated HOMO and LUMO energies illustrate that charge transfer within the molecule. Molecular electrostatic potential (MEP) were also performed.
\end{abstract}

Index Terms-DFT, NBO, NLO, MEP, HOMO-LUMO.

\section{INTRODUCTION}

Cinnoline derivatives are an important class of compound possessing a wide variety of biological activities such as antibacterial and antifungi activities [1,2]. Investigations on structures of Cinnoline derivatives have attracted the attention due to their peculiar properties and pharmacological uses. Cinnoline and related compounds pointed out that this ring system was the least known of the condensed, bicyclic aromatic heterocycles containing two nitrogen atoms. Some cinnolines have been screened and have received approval as bioactive drugs or are still under clinical trials [3]. Its chemical formula is C9H6N2O2. Literature survey reveals that to the best of our knowledge, there is no DFT studies, vibrational assignments, NLO activity and molecular docking studies for title compound CN4C.

Nowdays, density functional theory (DFT) method becomes the most popular and versatile quantum mechanical modeling method to investigate the electronic structure. Also, the natural bond orbital investigation (NBO) has been performed to get accurate information regarding the hybridization and hydrogen bond interaction energies. In addition to these, the HOMO-LUMO energy gap has been computed to provide the information regarding the charge transfer within the molecule. The other important quantities such as softness (S), hardness $(\eta)$, electron affinity(A), ionization potential(I), chemical potential $(\mu)$, electrophilicity index $(\omega)$, electronegativity $(\chi)$, are also calculated in the way of molecular orbital framework.
*Corresponding author: S. Muthu, Email: mutgee@gmail.com

\section{COMPUTATIONAL METHODS}

Density Functional Theoretical (DFT) quantum chemical computations were carried out at the Becke3Lee-Yang-parr(B3LYP) level with 6-311++G(d,p) basis set using Gaussion 09 program package [4] to get a clear knowledge of optimized parameters. NBO calculations [5] were performed using NBO 3.1 Program to understand inter and intra-molecular delocalization or hyperconjugation [6-9]. The first hyper polarizabilities and related properties $\left(\beta_{\text {tot }} \alpha, \Delta \alpha\right)$ of title compound $\mathrm{CN} 4 \mathrm{C}$ were calculated using B3LYP/ 6-311++G(d,p) basis set. The electronic properties such as HOMO and LUMO energies were determined by DFT approach.

\section{RESULTS AND DISCUSSION}

\section{A. Molecular geometry}

The geometrical parameters of the CN4C molecules are listed in Table 1 using DFT/B3LYP method with $6-311++G(d, p)$ basis set. The optimized molecular structure of cinnoline-4-carboxylic acid is obtained from Gaussian 09W and Gauss View 5.0 programs are shown in Fig.1. The theoretical investigation were carried out isolated molecule in the gas phase. This title molecule has nine $\mathrm{C}-\mathrm{C}$ bond lengths, five $\mathrm{C}-\mathrm{H}$ bond lengths, two $(\mathrm{C}$ $\mathrm{N}, \mathrm{C}-\mathrm{O})$ bond lengths and one $(\mathrm{N}-\mathrm{N}, \mathrm{O}-\mathrm{H})$ bond lengths respectively. The highest bond length was calculated for $\mathrm{N} 1$ - N2, C6-C7, C7-C8, C8-C9 found to be 1.403 and $1.402 \AA$ respectively. The calculated bond length values for $\mathrm{C}-\mathrm{C}$ in the benzene ring vary from 
1.355-1.402 ̊ and C-H bond length calculated at $1.070 \AA$ by B3LYP/6-311++G(d,p) basis set. The homonuclear bond lengths (C-C and $\mathrm{N}-\mathrm{N})$ are higher and heteronuclear bond lengths $(\mathrm{C}-\mathrm{H}, \mathrm{N}-\mathrm{C}$ and $\mathrm{C}-\mathrm{O})$ are lower. The important reason for the like charges is repulsive and the forces of unlike charges are attractive.

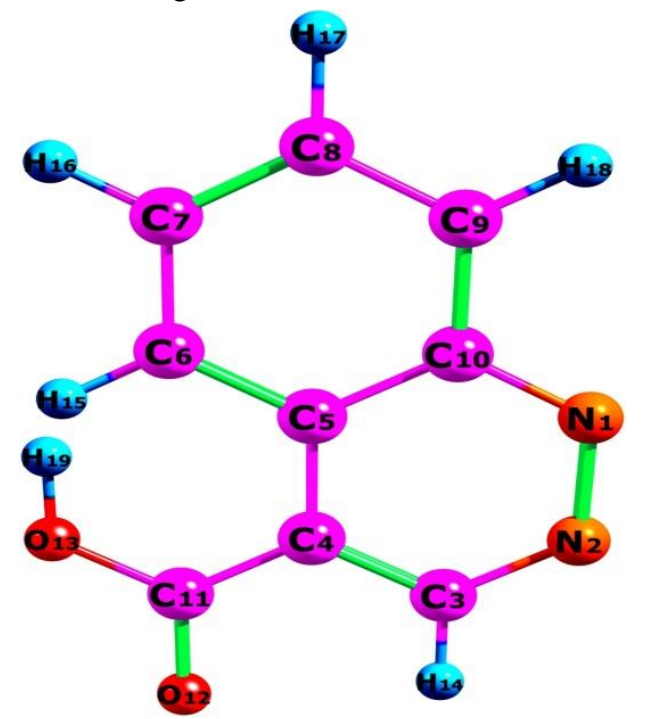

Figure 1: Optimized geometric structure with atoms numbering of $\mathrm{CN} 4 \mathrm{C}$

\section{B. Hyperpolarizability calculations}

The first order hyperpolarizability $\left(\beta_{\text {total }}\right)$ of the $\mathrm{CN} 4 \mathrm{C}$ along with related properties $(\mu, \alpha$ and $\Delta \alpha)$ are investigated by DFT/ Becke-3-Lee-Yang-Parr method with $6-311++\mathrm{G}(\mathrm{d}, \mathrm{P})$ basis set, is based on the finite-field approach. NLO activity arises from the interactions of electromagnetic fields in different media to produce latest fields changed in phase, frequency, amplitude or other propagation characteristics' from the incident fields. Nonlinear optical effects (NLO) is at the forefront of the recent investigation because of its significance in bestowing the key functions of optical modulation, optical logic, optical memory, optical switching and frequency shifting for the presently growing technologies in areas such as telecommunications, signal processing, and optical interconnections [10,11].

The non-linear optical response of an isolated molecule in an electric field $\mathrm{E}_{\mathrm{i}}(\omega)$ can be represented as a Taylor series enlargement of the total dipole moment, $\mu_{\text {tot}}$, induced by the field:

$$
\mu_{\text {tot }}=\mu_{0}+\alpha_{i j} E_{j}+\beta_{i j k} E_{j} E_{k}+\ldots,
$$

Where $\alpha$ is the linear polarizability, $\mu_{0}$ is the permanent dipole moment and $\beta_{\mathrm{ijk}}$ are the first hyperpolarizability tensor components. The isotropic (or average) linear polarizability is defined as:

$$
\alpha=\frac{\alpha_{x x}+\alpha_{y y}+\alpha_{z z}}{3}
$$

The first order hyperpolarizability is a third rank tensor that can be explained by $3 \times 3 \times 3$ matrix. The 27 components of $3 \mathrm{D}$ matrix can be abridged to 10 components owing to the Kleinman symmetry [12]

.Components of the first hyperpolarizability can be calculated using the following equation:

$$
\left.\beta_{i}=\beta_{i i i}+\sum_{i \neq j}\left(\beta_{i j j}+\beta_{j i j}+\beta_{j j i}\right)_{\mathrm{jij}+} \beta_{\mathrm{jji}}\right)
$$

Using the $\mathrm{x}, \mathrm{y}$ and $\mathrm{z}$ components of $\beta$, the magnitude of the first hyperpolarizability tensor can be calculated by:

\begin{tabular}{|c|c|c|c|}
\hline \multicolumn{4}{|c|}{ B3LYP/6-311++G(d,p) } \\
\hline Parameters & Bond length $(\AA)$ & Parameters & Bond angle $\left(^{\circ}\right)$ \\
\hline N1-N2 & 1.403 & N2-N1-C10 & 120.1 \\
\hline N1-C10 & 1.337 & N1-N2-C3 & 120.8 \\
\hline $\mathrm{N} 2-\mathrm{C} 3$ & 1.341 & N1-C10-N5 & 119.6 \\
\hline $\mathrm{C} 3-\mathrm{C} 4$ & 1.356 & N1-C10-C9 & 120.3 \\
\hline C3-H14 & 1.070 & $\mathrm{~N} 2-\mathrm{C} 3-\mathrm{C} 4$ & 120.4 \\
\hline C4-C5 & 1.399 & N2-C3-H14 & 119.8 \\
\hline C4-C11 & 1.355 & C4-C3-H14 & 119.8 \\
\hline C5-C6 & 1.401 & C3-C4-C5 & 119.8 \\
\hline $\mathrm{C} 5-\mathrm{C} 10$ & 1.397 & $\mathrm{C} 3-\mathrm{C} 4-\mathrm{C} 11$ & 120.1 \\
\hline C6-C7 & 1.402 & $\mathrm{C} 5-\mathrm{C} 4-\mathrm{C} 11$ & 120.1 \\
\hline C6-H15 & 1.070 & $\mathrm{C} 4-\mathrm{C} 5-\mathrm{C} 6$ & 120.4 \\
\hline $\mathrm{C} 7-\mathrm{C} 8$ & 1.402 & $\mathrm{C} 4-\mathrm{C} 5-\mathrm{C} 10$ & 119.4 \\
\hline C7-H16 & 1.070 & $\mathrm{C} 4-\mathrm{C} 11-\mathrm{O} 12$ & 120.0 \\
\hline $\mathrm{C} 8-\mathrm{C} 9$ & 1.402 & $\mathrm{C} 4-\mathrm{C} 11-\mathrm{O} 13$ & 120.0 \\
\hline C8-H17 & 1.070 & C6-C5-C10 & 120.1 \\
\hline C9-C10 & 1.401 & C5-C6-C7 & 119.9 \\
\hline C9-H18 & 1.070 & C5-C6-H15 & 120.1 \\
\hline C11-O12 & 1.258 & C5-C10-C9 & 120.1 \\
\hline $\mathrm{C} 11-\mathrm{O} 13$ & 1.301 & C7-C6-H15 & 120.1 \\
\hline \multirow[t]{11}{*}{ O13-H19 } & 0.960 & $\mathrm{C} 6-\mathrm{C} 7-\mathrm{C} 8$ & 120.0 \\
\hline & & C6-C7-H16 & 120.0 \\
\hline & & C8-C7-H16 & 120.0 \\
\hline & & C7-C8-C9 & 120.0 \\
\hline & & C7-C8-H17 & 120.0 \\
\hline & & C9-C8-H17 & 120.0 \\
\hline & & C8-C9-C10 & 119.9 \\
\hline & & C8-C9-H18 & 120.0 \\
\hline & & C10-C9-H18 & 120.0 \\
\hline & & O12-C11-O13 & 120.0 \\
\hline & & C11-O13-H19 & 120.0 \\
\hline
\end{tabular}

$$
\beta_{\text {tot }}=\sqrt{\left(\beta_{x}^{2}+\beta_{y}^{2}+\beta_{z}^{2}\right)}
$$

The entire equation for reckoning the magnitude of $\beta$ from

Geometrical parameters optimized in cinnoline-4-carboxylic acid (CN4C) bond length $(\AA)$ and bond angle (o) with 6-311++G(d,P) basis set.

Gaussian 09W program output is given a follows:

$$
\beta_{t o t}=\sqrt{\left(\beta_{x x x}+\beta_{x y y}+\beta_{x z z}\right)^{2}+\left(\beta_{y y y}+\beta_{y z z}+\beta_{x x y}\right)^{2}+\left(\beta_{z z z}+\beta_{x x z}+\beta_{y y z}\right)^{2}}
$$

The calculations of the total molecular dipole moment $(\mu)$, linear polarizability $(\alpha)$ and first-order hyperpolarizability $(\beta)$ from the Gaussian output have been explained in detail previously [13], and DFT has been widely used as an efficient method to investigate the 
organic non-linear optical materials [14,15]. In addition, the polar properties of the CN4C were computed at the DFT (B3LYP)/6-311++G(d,p) level using Gaussian 09W program package.

Table 2

The values of calculated dipole moment $\mu$ (D), polarizability $\left(\alpha_{0}\right)$, first order hyperpolarizability ( $\beta$ tot) components of $\mathrm{CN} 4 \mathrm{C}$.

\begin{tabular}{|c|c|c|c|}
\hline Parameters & B3LYP/6-311++G(d,p) & Parameters & B3LYP/6-311++G(d, \\
\hline$\mu_{\mathrm{x}}$ & -2.3846 & $\beta_{x x x}$ & 137.5768 \\
\hline$\mu_{\mathrm{y}}$ & -1.4185 & $\beta_{x x y}$ & -100.8850 \\
\hline$\mu \mathrm{z}$ & 0 & $\beta_{x y y}$ & 92.05543 \\
\hline$\mu(D)$ & 2.7746 & $\beta_{y y y}$ & -1019.3400 \\
\hline$\alpha_{x x}$ & 178.0215 & $\beta_{z x x}$ & -63.7273 \\
\hline$\alpha_{\mathrm{xy}}$ & -11.8985 & $\beta_{\mathrm{xyz}}$ & -185.4690 \\
\hline$\alpha_{y y}$ & 140.2307 & $\beta_{z y y}$ & -157.8390 \\
\hline$\alpha_{x z}$ & 0 & $\beta_{\mathrm{xzz}}$ & 8.5535 \\
\hline$\alpha_{y z}$ & 0 & $\beta_{y z z}$ & -301.3370 \\
\hline$\alpha_{z z}$ & 61.0276 & $\beta_{z z z}$ & 0 \\
\hline$\alpha_{0}($ e.s.u $)$ & $1.8736 \times 10^{-23}$ & $\beta$ tot (e.s.u) & $12.5990 \times 10^{-30}$ \\
\hline$\alpha$ (e.s.u) & $4.8198 \times 10^{-23}$ & & \\
\hline
\end{tabular}

Urea is the ideal molecule utilized in examining of the NLO properties of the compound. For this reason, urea was used often as a threshold value for comparative purpose. The calculated dipole moment and hyperpolarizability values obtained from B3LYP/6$311++\mathrm{G}(\mathrm{d}, \mathrm{p})$ methods are collected in Table 2 . The first order hyperpolarizability of $\mathrm{CN} 4 \mathrm{C}$ with B3LYP/6$311++\mathrm{G}(\mathrm{d}, \mathrm{p})$ basis set is $12.5990 \times 10^{-30}$ Thirty seven times greater than the value of urea $\left(\beta_{o}=0.372 \times 10^{-30}\right.$ esu). From the computation, the high values of the hyperpolarizabilities of $\mathrm{CN} 4 \mathrm{C}$ are probably attributed to the charge transfer existing amid the benzene rings within the molecular skeleton. This is evidence for the nonlinear optical (NLO) property of the molecule.

\section{NBO analysis}

NBO study provides the most accurate result possible 'natural Lewis structure' picture of $\varphi$, because all orbital information are mathematically chosen to include the highest possible percentage of the electron density. A helpful of the natural bond orbital method is that it gives information about intra- and intermolecular interactions in both filled. The second-order Fock matrix was carried out to evaluate the donor-acceptor interactions in the NBO analysis [16]. The interactions result is a loss of occupancy from the localized NBO of the romanticize Lewis structure into an empty non-Lewis orbital. For each acceptor (j), donor (i) and the stabilization energy $E(2)$ associated with the delocalization $\mathrm{i} \rightarrow \mathrm{j}$ is predicted as

$$
\mathrm{E}_{2}=\Delta \mathrm{E}_{\mathrm{ij}}=\mathrm{q}_{\mathrm{i}} \frac{\mathrm{F}(\mathrm{i}, \mathrm{j})^{2}}{\mathrm{E}_{\mathrm{i}}-\mathrm{E}_{\mathrm{j}}}
$$

Where $q_{i}$ is the donor orbital occupancy, $E_{i}$ and $E j$ are diagonal elements and $F(i, j)$ is the off diagonal NBO Fock matrix elements.

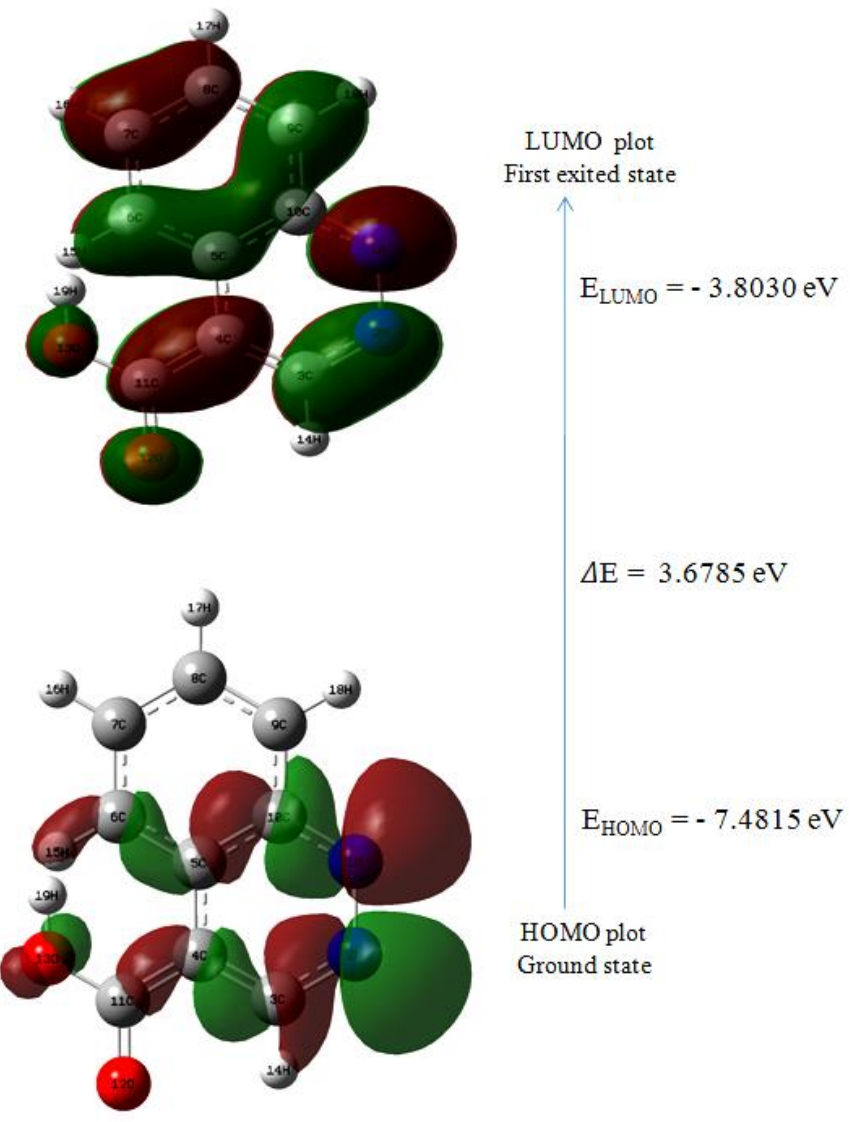

Figure 2: Atomic orbital HOMO - LUMO composition of the frontier molecular orbital for CN4C

NBO analysis provides an inter and intra molecular bonding and interaction among bonds, and also provides a suitable basis for examining charge transfer or conjugative interaction in molecular systems. The interacting stabilization energy, some electron acceptor orbital and donor orbital resulted from the second-order micro-disturbance theory are reported $[17,18]$. The higher the $E(2)$ value, the molecular interaction between electron donors and electron acceptors is more intensive and the greater the extent of conjugation of the entire system. Delocalization of electron density amid occupied Lewistype (bond or lone pair) NBO orbitals and properly unoccupied (antibond or Rydgberg) non-Lewis NBO orbitals resemble to a stabilizing donor-acceptor interaction. NBO analysis has been performed on the title molecule at the B3LYP/6-311++G(d,p) level in order to elucidate the intra molecular, rehybridization and 
delocalization of electron density within the molecule. Table 3

Second order perturbation theory analysis of Fock matrix in NBO basis for CN4C.

\begin{tabular}{|c|c|c|c|}
\hline Donor(i) & Type & $\mathrm{ED} / \mathrm{e}$ & Acceptor(i) \\
\hline $\mathrm{N}_{1}-\mathrm{N}_{2}$ & $\sigma$ & 1.9841 & $\mathrm{C}_{9}-\mathrm{C}_{10}$ \\
\hline $\mathrm{N}_{1}-\mathrm{C}_{10}$ & $\sigma$ & 1.9874 & $\begin{array}{l}\mathrm{C}_{5}-\mathrm{C}_{6} \\
\mathrm{C}_{5}-\mathrm{C}_{10}\end{array}$ \\
\hline $\mathrm{N}_{1}-\mathrm{C}_{10}$ & $\pi$ & 1.6421 & $\begin{array}{l}\mathrm{C}_{9}-\mathrm{C}_{10} \\
\mathrm{~N}_{2}-\mathrm{C}_{3} \\
\mathrm{C}_{4}-\mathrm{C}_{5} \\
\mathrm{C}_{2}-\mathrm{C}_{9}\end{array}$ \\
\hline $\mathrm{N}_{2}-\mathrm{C}_{3}$ & $\pi$ & 1.6478 & $\begin{array}{l}\mathrm{N}_{1}-\mathrm{C}_{10} \\
\mathrm{C}_{4}-\mathrm{C}_{5}\end{array}$ \\
\hline $\mathrm{C}_{3}-\mathrm{C}_{4}$ & $\sigma$ & 1.9732 & $\begin{array}{l}\mathrm{C}_{4}-\mathrm{C}_{5} \\
\mathrm{C}_{4}-\mathrm{C}_{11}\end{array}$ \\
\hline $\mathrm{C}_{3}-\mathrm{H}_{14}$ & $\sigma$ & 1.9744 & $\mathrm{~N}_{1}-\mathrm{N}_{2}$ \\
\hline $\mathrm{C}_{4}-\mathrm{C}_{5}$ & $\sigma$ & 1.9632 & $\begin{array}{c}\mathrm{C}_{3}-\mathrm{C}_{4} \\
\mathrm{C}_{5}-\mathrm{C}_{10}\end{array}$ \\
\hline $\mathrm{C}_{4}-\mathrm{C}_{5}$ & $\pi$ & 1.5376 & $\begin{array}{c}\mathrm{N}_{1}-\mathrm{C}_{10} \\
\mathrm{~N}_{2}-\mathrm{C}_{3} \\
\mathrm{C}_{6}-\mathrm{C}_{7} \\
\mathrm{C}_{11}-\mathrm{O}_{12}\end{array}$ \\
\hline $\mathrm{C}_{6}-\mathrm{C}_{7}$ & $\pi$ & 1.7316 & $\begin{array}{l}\mathrm{C}_{4}-\mathrm{C}_{5} \\
\mathrm{C}_{8}-\mathrm{C}_{9}\end{array}$ \\
\hline $\mathrm{C}_{8}-\mathrm{C}_{9}$ & $\pi$ & 1.7032 & $\begin{array}{l}\mathrm{N}_{1}-\mathrm{C}_{10} \\
\mathrm{C}_{6}-\mathrm{C}_{7}\end{array}$ \\
\hline $\mathrm{N}_{1}$ & $\mathrm{LP}(1)$ & 1.9452 & $\mathrm{C}_{5}-\mathrm{C}_{10}$ \\
\hline $\mathrm{N}_{2}$ & $\mathrm{LP}(1)$ & 1.9484 & $\begin{array}{l}\mathrm{N}_{1}-\mathrm{C}_{10} \\
\mathrm{C}_{3}-\mathrm{C} 4\end{array}$ \\
\hline $\mathrm{O}_{12}$ & $\mathrm{LP}(2)$ & 1.8815 & $\begin{array}{c}\mathrm{C}_{4}-\mathrm{C}_{11} \\
\mathrm{C}_{11}-\mathrm{O}_{13}\end{array}$ \\
\hline $\mathrm{O}_{13}$ & $\mathrm{LP}(1)$ & 1.9611 & $\mathrm{C}_{4}-\mathrm{C}_{11}$ \\
\hline $\mathrm{O}_{13}$ & $\mathrm{LP}(2)$ & 1.7857 & $\mathrm{C}_{11}-\mathrm{O}_{12}$ \\
\hline $\mathrm{N}_{1}-\mathrm{C}_{10}$ & $\pi^{*}$ & 0.4029 & $\begin{array}{l}\mathrm{C}_{4}-\mathrm{C}_{5} \\
\mathrm{C}_{8}-\mathrm{C}_{9}\end{array}$ \\
\hline $\mathrm{N}_{2}-\mathrm{C}_{3}$ & $\pi^{*}$ & 0.3169 & $\mathrm{C}_{4}-\mathrm{C}_{5}$ \\
\hline $\mathrm{C}_{6}-\mathrm{C}_{7}$ & $\pi^{*}$ & 0.2794 & $\begin{array}{l}\mathrm{C}_{4}-\mathrm{C}_{5} \\
\mathrm{C}_{8}-\mathrm{C}_{9}\end{array}$ \\
\hline $\mathrm{C}_{6}-\mathrm{H}_{15}$ & $\sigma$ & 1.8458 & $\mathrm{H}_{19}$ \\
\hline $\mathrm{O}_{13}$ & $\mathrm{LP}(1)$ & 1.9611 & $\mathrm{H}_{19}$ \\
\hline $\mathrm{O}_{13}$ & $\mathrm{LP}(3)$ & 1.5005 & $\mathrm{H}_{19}$ \\
\hline
\end{tabular}

$\mathrm{E}^{(2)}$ means energy of hyper conjugative interaction (stabilization energy)
${ }^{\circ}$ Energy difference between donor and acceptor $i$ and $\mathrm{j}$ NBO orbitals.
${ }^{c} \mathrm{~F}(\mathrm{i}, \mathrm{j})$ is the Fock matrix element between $\mathrm{i}$ and $\mathrm{j}$ NBO orbitals

the $\sigma$ and $\pi$ electrons of C-C to the anti $\mathrm{C}-\mathrm{C}$ bond of the ring leads to stabilization energy listed in Table 3. The strong intramolecular hyperconjugative interaction of $\sigma$ $\left(\mathrm{C}_{4}-\mathrm{C}_{5}\right)$ distributes to $\sigma{ }^{*}\left(\mathrm{C}_{3}-\mathrm{C}_{4}\right)$ and $\left.\mathrm{C}_{5}-\mathrm{C}_{10}\right)$ of the ring. On the other hand, side the $\pi\left(\mathrm{C}_{4}-\mathrm{C}_{5}\right)$ in the ring conjugate to the anti-bonding orbital of $\pi^{*}\left(\mathrm{~N}_{1}-\mathrm{C}_{10}\right)$, $\pi^{*}\left(\mathrm{~N}_{2}-\mathrm{C}_{3}\right)$ and $\pi^{*}\left(\mathrm{C}_{6}-\mathrm{C}_{7}\right)$ which leads to strong delocalization of $22.540,26.420$ and $18.370 \mathrm{~kJ} / \mathrm{mol}$ respectively. $\mathrm{LP}$ (2) $\mathrm{O}_{13}$ antibonding acceptor $\pi^{*}\left(\mathrm{C}_{11}-\right.$ $\mathrm{O}_{12}$ ) of the $\mathrm{CN} 4 \mathrm{C}$ energy of $54.430 \mathrm{~kJ} / \mathrm{mol}$. The high interaction energy of title molecule is electrons donating from $\mathrm{LP}(3)$ to the acceptor $\mathrm{LP}^{*}(1)$ with large stabilization energy of $612.850 \mathrm{~kJ} / \mathrm{mol}$ as shown in Table 3.

\section{HOMO - LUMO energy}

The fundamental importance of HOMO and LUMO understands the chemical stability and reactivity of many organic molecules. The energy gap between the HOMOs and LUMOs is the congested parameters in deciding molecular electrical transport properties assist in the measure of electron conductivity [19]. The HOMO energy illustrates the ability of electron donor unit, the LUMO illustrate the ability of the electron acceptor unit. HOMO and LUMO is related to the ionization potential and electron affinity. The energy difference between HOMO and LUMO energy is called as energy gap that is important stability for structure [20]. The total energy, HOMO and LUMO energies, the energy gap $(\Delta \mathrm{E})$, the ionization potential (I), the electron affinity (A), the absolute electronegativity $(\chi)$, the absolute hardness $(\eta)$ and softness $(\mathrm{S})$ for the $\mathrm{CN} 4 \mathrm{C}$ molecule have been
The strong intramolecular hyper conjugative interaction of

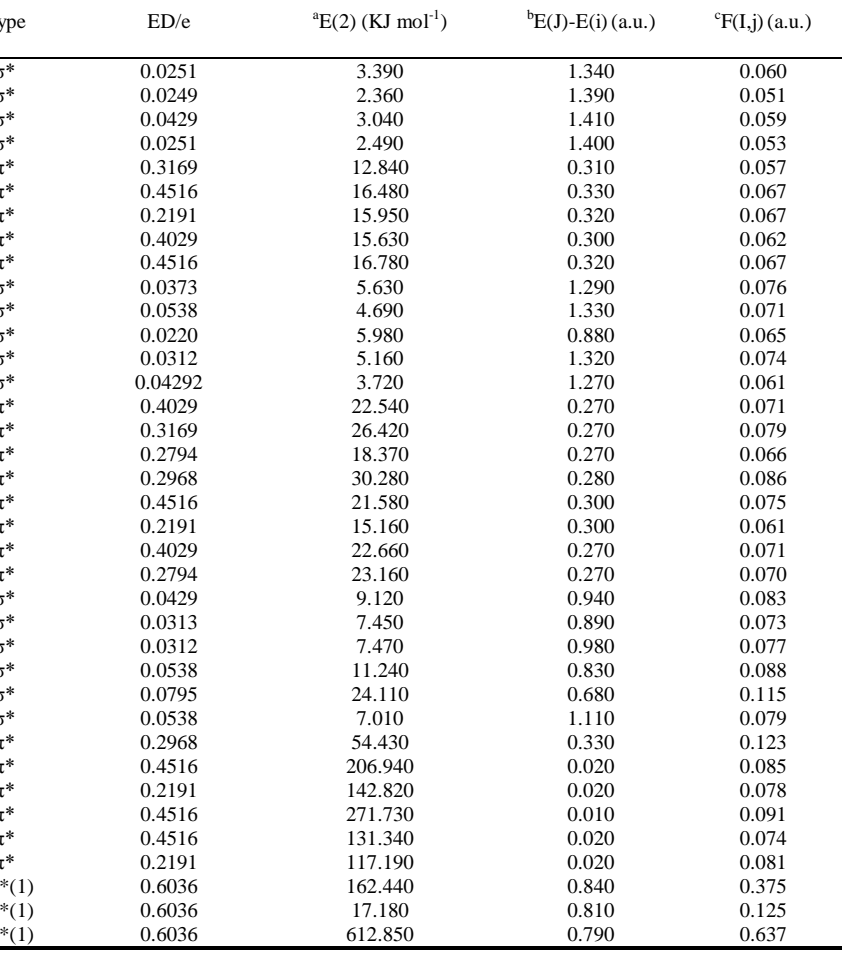

calculated at B3LYP/6-311++G(d,P) basis set (Fig. 2) and the result are given in Table 4.

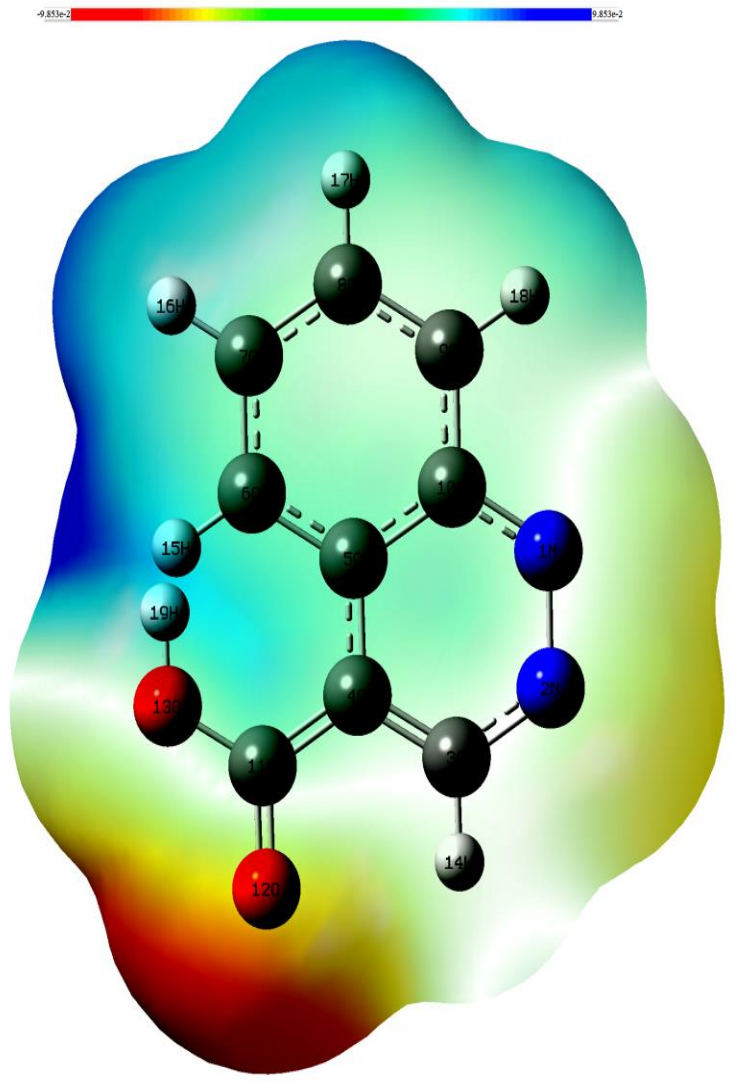

Figure 3: Total electron density mapped with molecular electrostatic potential surface of $\mathrm{CN} 4 \mathrm{C}$

By using HOMO and LUMO energy values for a molecule, electronegativity and chemical hardness canbe calculated as follow: 
$\chi=(\mathrm{I}+\mathrm{A}) / 2$ (Electronegativity)

$\mu=-(\mathrm{I}+\mathrm{A}) / 2($ Chemical potential)

$\eta=(\mathrm{I}-\mathrm{A}) / 2$ (Chemical hardness)

Calculated energy values of title compound by B3LYP/6-311++G(d,p) method.

\begin{tabular}{cc}
\hline Basis set & B3LYP/6-311++G(d,p) \\
\hline Eномо $(\mathrm{eV}) \mathrm{E}_{\mathrm{LUMO}}(\mathrm{eV})$ & -7.4815 \\
Ionization potential & -3.8030 \\
Electron affinity & 7.4815 \\
Energy gap (eV) & 3.8030 \\
Electronegativity & 3.6785 \\
Chemical potential & 5.6422 \\
Chemical hardness & -5.6422 \\
Chemical softness & 1.8392 \\
Electrophilicity index & 0.2718 \\
$\mathrm{~S}=1 / 2 \eta($ chemical softness) & 8.6543 \\
$\omega=\mu^{2} / 2 \eta($ Electrophilicity index)
\end{tabular}

Where $\mathrm{I}$ and $\mathrm{A}$ are ionization potential and electron affinity; $\mathrm{I}=-\mathrm{E}_{\mathrm{HOMO}}$ and $\mathrm{A}=-\mathrm{E}_{\mathrm{LUMO}}$ respectively [21]. The HOMO and LUMO are delocalized over the entire molecule. The lowest unoccupied molecular orbital (LUMO) energy is $-3.8030 \mathrm{eV}$ and the highest occupied molecular orbital (HOMO) energy is $-7.4815 \mathrm{eV}$. According to DFT calculation, the frontier orbital energy gap of $\mathrm{CN} 4 \mathrm{C}$ is found to be $3.6785 \mathrm{eV}$. This smaller energy gap of HOMO-LUMO explains the eventual charge transfer occurs within the molecule, which influences its high polarizability and biological activities.

\section{E. Molecular electrostatic potential (MEP)}

At any given point $\mathrm{r}(\mathrm{x}, \mathrm{y}, \mathrm{z})$ in the vicinity of a molecule, the molecular electrostatic potential, $v(r)$ is defined in terms of the interaction energy between the electrical charge generated from the molecule electrons and nuclei and a positive test charge (a proton) located at $r$ [22,23]. The molecular electrostatic potential (MEP) is related to the electronic density and a very useful descriptor for determining sites for electrophilic attack and nucleophilic reactions as well as hydrogen-bonding interactions [24,25]. In the present study, 3D plots of molecular electrostatic potential (MEP) of CN4C are illustrated in Fig. 3. The different value of electrostatic potential at the surface is represented by different colors. Potential increases in the order red < orange < yellow < blue. The color code of these maps in the range between $9.853 \mathrm{eV}$ and $+9.853 \mathrm{eV}$ in compound, where blue indicates the strongest attraction and yellow indicates repulsion. As can be seen from the MEP of the title compound while region having the negative potential are over the electronegative atoms (Nitrogen, Oxygen atom), the region having the positive potential are over the hydrogen atom. From this result, we can say that the $\mathrm{H}$ atom indicates the strongest attraction and Nitrogen, Oxygen atoms the repulsion.

\section{CONCLUSION}

The optimized molecular structure, Natural bond orbital and electronic properties of cinnoline-4carboxylic acid are calculated by DFT method using B3LYP/6-311++G(d,p) basis set. The optimized geometric parameters (bond lengths and bond angles) are theoretically determined by DFT theory. The lowering of the HOMO-LUMO energy gap value has substantial influence on the intermolecular charge transfer and bioactivity of the molecule. The NBO analysis indicates the intermolecular charge transfer between the bonding and antibonding orbitals. The electronic dipole moment, polarizabilities and the hyperpolarizabilities of the compound studied. The MEP map shows the negative potential sites are on Nitrogen and Oxygen atoms as well as the positive potential sites around the hydrogen atoms

\section{REFERENCES}

[1] V.P.Gopika, G.Havisha, S.Muthu, M. Raja, R. Raj Muhamed, "Molecular structure, NBO, first order hyperpolarizability and HOMO-LUMO analysis of 7Azathieno[2,3-c]cinnoline", Int.J. ChemTech Res. 8(12) (2015) 721-733.

[2] L.K. Hansen, V. Stockmann, A. Fiksdahl, "7Azathieno[2,3-c]cinnoline", Actacryst E63 (2007) o3896.

[3] W. Lewgowd, A. Stanczak, "Cinnoline Derivatives with Biological Activity”, Arch. Pharm. Chem. Life Sci. 340 (2007) 65-80.

[4] M. J. Frisch, G. W. Trucks, H. B. Schlegel, G. E. Scuseria, M. A. Robb, J. R. Cheeseman, G. Scalmani, V. Barone, B. Mennucci, G. A. Petersson, H. Nakatsuji, M. Caricato, X. Li, H. P. Hratchian, A. F. Izmaylov, J. Bloino, G. Zheng, J. L. Sonnenberg, M. Hada, M. Ehara, K. Toyota, R. Fukuda, J. Hasegawa, M. Ishida, T. Nakajima, Y. Honda, O. Kitao, H. Nakai, T. Vreven, J. A. Montgomery, Jr., J. E. Peralta, F. Ogliaro, M. Bearpark, J. J. Heyd, E. Brothers, K. N. Kudin, V. N. Staroverov, R. Kobayashi, J. Normand, K. Raghavachari, A. Rendell, J. C. Burant, S. S. Iyengar, J. Tomasi, M. Cossi, N. Rega, J. M. Millam, M. Klene, J. E. Knox, J. B. Cross, V. Bakken, C. Adamo, J. Jaramillo, R. Gomperts, R. E. Stratmann, O. Yazyev, A. J. Austin, R. Cammi, C. Pomelli, J. W. Ochterski, R. L. Martin, K. Morokuma, V. G. Zakrzewski, G. A. Voth, P. Salvador, J. J. Dannenberg, S. Dapprich, A. D. Daniels, Ö. Farkas, J. B. Foresman, J. V. Ortiz, J. Cioslowski, and D. J. Fox, Gaussian 09, Revision E.01, Gaussian, Inc., Wallingford CT, 2009.

[5] E.D. Glendening, A.E. Reed, J.E. Carpenter, F. Weinhold, "NBO Version 3.1", Theoretical Chemistry Institute and Department of Chemistry, University of Wisconsin, Madison, 1998. 
[6] E. Runge, E.K.U. Gross, "Density-functional theory for time-dependent systems",Phys. Rev. Lett. 52 (1984) 9971000.

[7] M. Petersilka, U.J. Gossmann, E.K.U. Gross, "Excitation energies from time-dependent density-functional theory",Phys. Rev. Lett. 76 (1966) 1212-1215.

[8] R. Bauernschmitt, R. Ahlrichs, "Treatment of electronic excitations within the adiabatic approximation of time dependent density functional theory", Chem. Phys. Lett. 256 (1996) 454-464.

[9] C. Jamorski, M.E. Casida, D.R. Salahub, "Dynamic polarizabilities and excitation spectra from a molecular implementation of time-dependent density-functional response theory: N2 as a case study", J. Chem. Phys. 104 (1996) 5134-5147.

[10] Y.X. Sun, Q.L. Hao, W. X. Wei, Z. X. YU, D.D. LU. X. Wang, Y. S. Wang, "Experimental and density functional studies on 4-(3,4-dihydroxybenzylideneamino)antipyrine, and 4-(2,3,4-trihydroxybenzylideneamino)antipyrine", J. Mol. Struct. Theochem. 904 (2009) 74-82.

[11] M. Nakano, H. Fujita, M. Takcathata, K. Yamaguchi, "Theoretical Study on Second Hyperpolarizabilities of Phenylacetylene Dendrimer: Toward an Understanding of Structure-Property Relation in NLO Responses of Fractal Antenna Dendrimers", J. Am. Chem. Soc. 124 (2002) 9648-9655.

[12] D. Sajan, H. Joe, V. S. Jajakumar, J. Zaleski, "Structural and electronic contributions to hyperpolarizability in methyl p-hydroxy benzoate", J. Mol. Struct. 785 (2006) 43-53.

[13] K. S. Thanthiri Watte, K. M. Nalin de silva, "Non-linear optical properties of novel fluorenyl derivatives-ab initio quantum chemical calculations", J. Mol. Struct. Theochem. 617 (2002) 169-175.

[14] S. G. Sagdinc, A. Esme, "Theoretical and vibrational studies of 4,5-diphenyl-2-2 oxazole propionic acid (oxaprozin)", Spectrochim. Acta Part A 75 (2010) 13701376.

[15] S. Muthu, G. Ramachandran, "Spectroscopic studies (FTIR, FT-Raman and UV-Visible), normal coordinate analysis, NBO analysis, first order hyper polarizability, HOMO and LUMO analysis of (1R)-N-(Prop-2-yn-1-yl)2,3-dihydro- $1 \mathrm{H}$-inden-1-amine molecule by ab initio $\mathrm{HF}$ and density functional methods", Spectrochim. Acta part A 121 (2014) 394-403.

[16] M. Szafran, A. Komasa, E.B. Adamska, "Crystal and molecular structure of 4-carboxypiperidinium chloride (4piperidinecarboxylic acid hydrochloride)", J. Mol. Struct. (THEOCHEM) 827 (2007) 101-107.

[17] C. James, A. Amal Raj, R. Reghunathan, I. Hubert Joe, V.S. Jayakumar, "Structural conformation and vibrational spectroscopic studies of 2, 6-bis (p-N, N-dimethyl benzylidene) cyclohexanone using density functional theory”, J. Raman. Spectrosc. 37 (2006) 1381-1392.

[18] J.N. Liu, Z.R. Chen, S.F. Yuan, J. Zhejiang, "Study on the prediction of visible absorption maxima of azobenzene compounds", Univ. Sci. B. 6 (2005) 584-589.

[19] R. Srinivasaraghavan, S. Thamaraikannan, S. Seshadri, T. Gnanasambandan, "Molecular conformational stability and Spectroscopic analysis of Parared with experimental techniques and quantum chemical calculations", Acta A 137 (2015) 1194-1205.

[20] D. F. V. Lewis, C. Loannides, D. V. Parke, "Interaction of a series of nitriles with the alcohol-inducible isoform of P450: Computer analysis of structure-activity relationships”, Xenobiotica 24 (1994) 401.

[21] R. G. Pearson, "Absolute electronegativity and hardness correlated with molecular orbital theory", Proc. Natl. Acad. Sci. 83 (1986) 8440-8441.

[22] P. Politzer, J.S. Murray, "The fundamental nature and role of the electrostatic potential in atoms and molecules", Theor. Chem. Acc. 108 (2002) 134-142.

[23] F.J. Luque, J.M. Lopez, M. Orozco, Perspective on "Electrostatic interactions of a solute with a continuum. A direct utilization of ab initio molecular potentials for the prevision of Solvent effects" - Miertus S, Scrocco E, Tomasi J (1981) ChemPhys 55:117, Theor. Chem. Acc. 10 (2000) 343-345.

[24] E. Scrocco, J. Tomasi, "Electronic molecular structure, reactivity and intermolecular forces: an euristic interpretation by means of electrostatic molecular potentials", Adv. Quantum Chem. 11 (1978) 115-121.

[25] N. Okulik, A.H. Jubert, "Theoretical analysis of the reactive sites of non-steroidal anti-inflammatory drugs", Internet Electr. J. Mol. Des. 4 (2005) 17-30. 